\title{
Summary of evidence-based guideline: Complementary and alternative medicine in multiple sclerosis: Report of the Guideline Development Subcommittee of the American Academy of Neurology
}

\section{Citation}

Yadav, V., C. Bever, J. Bowen, A. Bowling, B. Weinstock-Guttman, M. Cameron, D. Bourdette, G. S. Gronseth, and P. Narayanaswami. 2014. "Summary of Evidence-Based Guideline: Complementary and Alternative Medicine in Multiple Sclerosis: Report of the Guideline Development Subcommittee of the American Academy of Neurology." Neurology 82 (12) (March 24): 1083-1092. doi:10.1212/wnl.0000000000000250.

\section{Published Version}

10.1212/wnl.0000000000000250

\section{Permanent link}

http://nrs.harvard.edu/urn-3:HUL.InstRepos:34298864

\section{Terms of Use}

This article was downloaded from Harvard University's DASH repository, and is made available under the terms and conditions applicable to Other Posted Material, as set forth at http:// nrs.harvard.edu/urn-3:HUL.InstRepos:dash.current.terms-of-use\#LAA

\section{Share Your Story}

The Harvard community has made this article openly available.

Please share how this access benefits you. Submit a story.

\section{Accessibility}




\section{Summary of evidence-based guideline: Complementary} and alternative medicine in multiple sclerosis

\section{Report of the Guideline Development Subcommittee of the American Academy of Neurology}

\section{妵会}

Vijayshree Yadav, MD, MCR

Christopher Bever, Jr., MD, MBA, FAAN

James Bowen, MD

Allen Bowling, MD, PhD

Bianca Weinstock-

Guttman, MD

Michelle Cameron, MD, PT

Dennis Bourdette, MD, FAAN

Gary S. Gronseth, MD, FAAN

Pushpa Narayanaswami, MBBS, DM, FAAN

Correspondence to American Academy of Neurology: guidelines@aan.com

\section{ABSTRACT}

Objective: To develop evidence-based recommendations for complementary and alternative medicine (CAM) in multiple sclerosis (MS).

Methods: We searched the literature (1970-March 2011; March 2011-September 2013 MEDLINE search), classified articles, and linked recommendations to evidence.

Results and recommendations: Clinicians might offer oral cannabis extract for spasticity symptoms and pain (excluding central neuropathic pain) (Level A). Clinicians might offer tetrahydrocannabinol for spasticity symptoms and pain (excluding central neuropathic pain) (Level B). Clinicians should counsel patients that these agents are probably ineffective for objective spasticity (short-term)/tremor (Level B) and possibly effective for spasticity and pain (longterm) (Level C). Clinicians might offer Sativex oromucosal cannabinoid spray (nabiximols) for spasticity symptoms, pain, and urinary frequency (Level B). Clinicians should counsel patients that these agents are probably ineffective for objective spasticity/urinary incontinence (Level B). Clinicians might choose not to offer these agents for tremor (Level C). Clinicians might counsel patients that magnetic therapy is probably effective for fatigue and probably ineffective for depression (Level B); fish oil is probably ineffective for relapses, disability, fatigue, MRI lesions, and quality of life (QOL) (Level B); ginkgo biloba is ineffective for cognition (Level A) and possibly effective for fatigue (Level C); reflexology is possibly effective for paresthesia (Level C); Cari Loder regimen is possibly ineffective for disability, symptoms, depression, and fatigue (Level C); and bee sting therapy is possibly ineffective for relapses, disability, fatigue, lesion burden/volume, and health-related QOL (Level C). Cannabinoids may cause adverse effects. Clinicians should exercise caution regarding standardized vs nonstandardized cannabis extracts and overall CAM quality control/nonregulation. Safety/efficacy of other CAM/CAM interaction with MS disease-modifying therapies is unknown. Neurology ${ }^{\circledR} 2014 ; 82: 1083-1092$

\section{GLOSSARY}

AAN = American Academy of Neurology; $\mathbf{A E}=$ adverse effect; $\mathbf{C A M}=$ complementary and alternative medicine; $\mathbf{C B D}=$ cannabidiol; $\mathbf{C l}=$ confidence interval; $\mathbf{D S M}-\mathbf{I V}$ = Diagnostic and Statistical Manual of Mental Disorders, 4th edition; EDSS = Expanded Disability Status Scale; FDA = US Food and Drug Administration; FSS = Fatigue Severity Scale; GB = ginkgo biloba; GNDS = Guy's Neurological Disability Scale; HRQOL = health-related QOL; MFIS = Modified Fatigue Impact Scale; MS = multiple sclerosis; MSIS = Multiple Sclerosis Impact Scale; OCE = oral cannabis extract; PPMS = primary progressive MS; $\mathbf{Q O L}$ = quality of life; $\mathbf{R C T}$ = randomized controlled trial; $\mathbf{R R M S ~ = ~ r e l a p s i n g - r e m i t t i n g ~ M S ; ~} \mathbf{S A E}$ = serious adverse effect; SPMS = secondary progressive MS; THC = tetrahydrocannabinol; VAS = visual analog scale.

Complementary and alternative medicine (CAM) therapies are nonconventional therapies used in addition to or instead of physician-recommended therapies. CAM use is prevalent in $33 \%-80 \%$ of patients with MS, ${ }^{1-10}$ particularly among those who are female, have higher education levels, and report poorer health. ${ }^{1-4,11}$ This document summarizes extensive information provided in the complete 
guideline, available as a data supplement on the Neurology ${ }^{\circledR}$ Web site at Neurology.org. Tables e-1 through e-3 and appendices e- 1 through e-6, cited in the full guideline (data supplement), as well as references e1-e84, cited in this summary, are available at Neurology.org.

This guideline addresses the following questions: In patients with MS,

1. do CAM therapies reduce specific symptoms and prevent relapses or disability?

2. can CAM use worsen MS or cause serious adverse effects (SAEs)?

3. can CAM use interfere with MS disease-modifying therapies?

DESCRIPTION OF THE ANALYTIC PROCESS This guideline was developed in accordance with the 2004 American Academy of Neurology (AAN) process manual. ${ }^{12}$ After review of conflict of interest statements, the AAN selected a panel of experts. A medical research librarian helped perform a comprehensive literature search, and the authors selected articles. At least 2 authors independently rated each article (AAN therapeutic classification scheme). We linked recommendation strength to the evidence quality. With regard to cannabis for pain, we reviewed studies evaluating pain associated with spasticity separately from those evaluating pain specified to be of central neuropathic origin and made separate recommendations. We performed Bonferroni correction for multiple comparisons when necessary.

ANALYSIS OF EVIDENCE Because studies were unavailable or, where available, had a high risk of bias, were in conflict, or lacked statistical precision, we found the evidence insufficient to support or refute the effectiveness of the following therapies in MS (table 1): acetyl-L-carnitine, acupuncture, biofeedback, carnitine, chelation therapy, Chinese medicine, chiropractic medicine, creatine monohydrate, dental amalgam replacement, glucosamine sulfate, hippotherapy, hyperbaric oxygen, inosine, linoleic acid, low-dose naltrexone, massage therapy, mindfulness training, music therapy, naturopathic medicine, neural therapy, Padma 28, progressive muscle relaxation therapy, tai chi, threonine, transdermal histamine, and yoga. Data also were insufficient to determine whether any CAM therapies worsen MS or interfere with disease-modifying therapies.

Evidence was available to develop practice recommendations for use of bee venom therapy, cannabinoids, ginkgo biloba (GB), lofepramine plus phenylalanine with $\mathrm{B}_{12}$ (Cari Loder regimen), low-fat diet with omega-3 supplementation, magnetic therapy, and reflexology (table 2). This evidence is discussed herein and includes only the studies that inform the conclusions and recommendations. We selected the final level of obligation for compliance with a recommendation (might/may, should, or must) after taking into consideration the quality of evidence (Level A, B, or C) and other factors (e.g., limited generalizability of the studies, safety/side effect concerns, availability of alternative treatments).

Cannabinoids. Cannabinoids are a group of compounds with psychoactive properties. Tetrahydrocannabinol (THC) and cannabidiol (CBD) are the major cannabinoids of cannabis. Synthetic cannabinoids are chemically related to THC. Orally administered cannabinoids (cannabis extract, synthetic THC), mucosally delivered cannabinoids (cannabis extract oral spray, nabiximols [trade name Sativex]), and smoked cannabis have all been studied for therapeutic effects in MS.

Oral cannabinoids (cannabis extract and THC). The search identified 9 studies (3 Class I, ${ }^{13-15} 2$ Class II, ${ }^{16,17}$ and 4 Class III' ${ }^{18-21}$ ).

A large Class I study ${ }^{13}(\mathrm{~N}=630$; patients with relapsing-remitting MS [RRMS], primary progressive MS [PPMS], and secondary progressive MS [SPMS]; 15 weeks) found that neither oral cannabis extract (OCE, THC with CBD) nor synthetic THC (Marinol) had greater effect than placebo on the primary outcome measure of spasticity as measured by total Ashworth scale $^{22}$ change from baseline (mean change \pm SD: OCE: 1.24 [6.60], THC: 1.86 [7.95], placebo: 0.92 $[6.56], p=0.40)$. However, in this same study, ${ }^{13}$ significantly more patients reported reduced spasticity symptoms in the treatment groups (secondary outcomes spasticity/pain: OCE [52/46\%], THC [51/ $50 \%$ ], placebo [37/30\%]). Sleep and muscle spasms also improved in the treatment groups.

In a second Class I study ${ }^{14}(\mathrm{~N}=249$; "stable MS," type unspecified; 12 weeks) the proportion of patients achieving relief of muscle stiffness was $29.4 \%$ in the OCE group compared with $15.7 \%$ in the placebo group (odds ratio 2.26, 95\% confidence interval [CI] CI 1.244.13). Secondary outcomes (muscle stiffness and spasms, pain, sleep) also improved in the cannabis group.

A third Class I study ${ }^{15}$ ( $\mathrm{N}=57$; RRMS, SPMS, PPMS), insufficiently powered, found no significant difference in objective spasticity (Ashworth scale) or patient-reported spasm frequency.

In both adequately powered Class I studies, ${ }^{13,14}$ significantly more patients treated with cannabinoids reported reduced pain, whereas disability measures and health questionnaire results were not significantly different between groups. One Class I study ${ }^{13}$ assessed tremor and bladder symptoms and noted no significant difference in outcomes between patients treated with cannabinoids and placebo.

Conclusions. OCE is established as effective for reducing patient-reported spasticity symptoms and pain 
Table 1 CAM therapies with insufficient evidence to support specific practice recommendations for their use in multiple sclerosis

\section{CAM intervention \\ Mind-body medicine \\ Biofeedback}

Music therapy

Mindfulness-based training

Hypnosis

Biologically based practices

Padma 28

Linoleic acid

Creatine monohydrate

Acetyl-L-carnitine

Inosine

Threonine

Glucosamine sulfate

Low-dose naltrexone

Transdermal histamine with caffeine

Hyperbaric oxygen therapy

Manipulative and body-based practices

Hippotherapy

Yoga
Description

Active physiologic monitoring of a body system (e.g., EMG activity). The results of the monitoring are provided to the patient in real time.

Uses music prescribed in a skilled manner by a music therapist

Mental training by nonjudgmental awareness of moment-to-moment experience by mindfulness exercises including observation of sensory, affective, and cognitive domains of perceptible experience

Induction followed by a series of suggestions for analgesia and comfort. Patients practiced the skills by listening to an audio recording and using a cue to reexperience hypnotic effects.
Ayurvedic mixture of 22 herbs $^{\mathrm{e} 43}$ with presumed immunologic effects on the suppressor lymphocytes and the endogenous interferon production ${ }^{\mathrm{e} 44}$

An unsaturated omega- 6 fatty acid

A naturally occurring nitrogenous organic compound involved in energy metabolism (phosphocreatine)

A naturally occurring compound that is the acetylated form of L-carnitine (synthesized from lysine and methione)

Ribosylated precursor of uric acid, which raises uric acid levels. Uric acid is a scavenger of peroxynitrate, a highly reactive compound postulated to cause potentially toxic changes in MS plaques, including nitration of tyrosine residues.

1 Class III ${ }^{\mathrm{e} 5}$

2 underpowered Class || $46, \mathrm{e} 47$ 2 Class III $48, \mathrm{e} 49$

1 underpowered Class $\|^{e 50}$ 1 underpowered Class IIIe5

1 underpowered Class I|e52

1 underpowered Class ||e53 3 conflicting Class III e54-e56

Naturally occurring amino acid observed to 1 Class III ${ }^{\text {57 }}$ increase glycine in rat spinal cord and therefore proposed as a treatment of spasticity

An amino sugar and a prominent precursor 1 Class $\left.\right|^{e 58}$ in the biochemical synthesis of glycosylated proteins and lipids, with potential immunoregulatory effects

Long-lasting opiate receptor antagonist; 1 underpowered Class le59 may intermittently block opiate receptors 1 underpowered Class ||e60 resulting in increased endogenous production of endorphins and opiate receptors, promoting psychological wellbeing and general health

Histamine is a neurotransmitter

1 Class III ${ }^{\mathrm{e} 1}$

1 Class I noninterpretable due to suboptimal control intervention (10\% oxygen with nitrogen) ${ }^{662}$

5 underpowered Class ||
MS types studied

Adverse effects

MSU

RRMS, PPMS, SPMS

RRMS, SPMS

Unspecified

None described
None described
Progressive MS, type unclear

MSU

RRMS, MSU

RRMS, SPMS

RRMS, SPMS

4/16 patients in 1 Class III study developed kidney stones ${ }^{\mathrm{e} 6}$
Progressive MS, type unspecified

RRMS

All MS subtypes
RRMS and progressive MS, type unspecified

MS type unspecified
Therapeutic horseback riding where the subject is described as being passive

Mind-body approach that has components of meditation, breathing, and postures
3 Class III ${ }^{\text {e68-e } 70} ; 1$ underpowered, 2 noninterpretable statistically evaluating effect on gait, balance, and mood

4 Class IIle71-e74; 3 underpowerede71, e $73, e 74$ evaluating effect on disability, spasticity, fatigue, cognition, mood, balance, and walking speed
RRMS, SPMS ${ }^{e 68}$ MS type unspecified ${ }^{69}$ All MS subtypes ${ }^{\mathrm{e} 0}$

\section{MS types}

unspecifiede $71, \mathrm{e} 72$

All MS subtypes ${ }^{\mathrm{e} 3, \mathrm{e} 74}$ 
Table 1 Continued

\begin{tabular}{|c|c|c|c|c|}
\hline CAM intervention & Description & Evidence & MS types studied & Adverse effects \\
\hline Massage therapy & & $\begin{array}{l}4 \text { Class III; mood }{ }^{\mathrm{e} 75} \text {; self-efficacy }{ }^{\mathrm{e} 76} \text {; } \\
\text { constipation }{ }^{777} ; \text { pain, fatigue, balance, } \\
\text { gait, and spasticity }\end{array}$ & 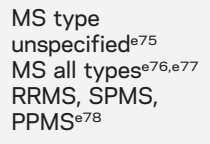 & \\
\hline Chinese acupuncture & $\begin{array}{l}\text { Procedures involving penetration of the } \\
\text { skin with needles in order to stimulate } \\
\text { certain points on the body }\end{array}$ & $\begin{array}{l}1 \text { Class III }{ }^{\text {e79 }} \text { evaluating effect on QOL } \\
\text { in SPMS }\end{array}$ & SPMS & \\
\hline $\begin{array}{l}\text { Progressive muscle relaxation } \\
\text { therapy }\end{array}$ & $\begin{array}{l}\text { Therapist instructs patients to contract and } \\
\text { release different muscle groups }\end{array}$ & $\begin{array}{l}1 \text { Class III evaluating effect on pain, } \\
\text { disability, spasms, fatigue, cognition, } \\
\text { and depression }{ }^{\mathrm{e} 1} \\
1 \text { Class III evaluating QOL }{ }^{\mathrm{e82}}\end{array}$ & $\begin{array}{l}\text { RRMS, SPMSe81; } \\
\text { RRMS, SPMS, } \\
\text { PPMS }\end{array}$ & \\
\hline \multicolumn{5}{|l|}{ Energy medicine } \\
\hline
\end{tabular}

Abbreviations: CAM = complementary and alternative medicine; $\mathrm{MS}=$ multiple sclerosis; $\mathrm{MSU}=\mathrm{MS}$ type unspecified; PPMS = primary progressive MS; $\mathrm{QOL}$ = quality of life; RRMS = relapsing-remitting MS; SPMS = secondary progressive MS.

Studies cited using reference list in summary guideline article (appearing in print).

(12-15 weeks; 2 Class I, ${ }^{13,14} 1$ Class III $\left.^{18}\right)$. This subjective benefit is possibly maintained for 1 year (1 Class $\mathrm{II}^{17}$ ).

THC is probably effective for reducing patientreported symptoms of spasticity and pain (15 weeks, 1 Class $\left.I^{13}\right)$. This subjective benefit is possibly maintained for 1 year (1 Class $\mathrm{II}^{17}$ ).

OCE and THC are probably ineffective for reducing both objective spasticity measures and MS-related tremor symptoms (15 weeks, 1 Class $\mathrm{I}^{13}$ ). OCE and THC are possibly effective for reducing symptoms and objective measures of spasticity over 1 year (1 Class $\left.\mathrm{II}^{17}\right)$.

Sativex oromucosal cannabinoid spray. The search identified 3 Class I, ${ }^{23-25} 2$ Class II, ${ }^{26,27}$ and 3 Class III ${ }^{28-30}$ studies in patients with MS, type unspecified.

A Class I study, a randomized controlled trial $(\mathrm{RCT})^{23}(\mathrm{~N}=160,6$ weeks), evaluated the effect of Sativex spray (GW Pharmaceuticals, Salisbury, UK) delivering THC $2.7 \mathrm{mg}$ and CBD $2.5 \mathrm{mg}$. Spasticity visual analog scale (VAS) was the only outcome measure on which scores improved significantly after Bonferroni correction (active -31.2 , placebo -8.4 , difference $-22.79,95 \% \mathrm{CI}-35.52$ to $-10.07, p=$ $0.001)$. Scores on physician-evaluated spasticity measures (Ashworth) did not change between groups.

A Class I RCT ${ }^{24}(\mathrm{~N}=66$, MS type unspecified, 5 weeks) in MS-related central neuropathic pain found that oromucosal cannabinoids were superior for reducing mean pain intensity (number needed to treat to reduce pain by 50\%: 3.7 [95\% CI 2.213]). Another Class I RCT ${ }^{25}$ ( $\mathrm{N}=135,10$ weeks, MS type unspecified) did not find improvement in the number of incontinence episodes with Sativex. However, the daily number of bladder voids (change from baseline: treatment -1.95 , placebo $-0.9 ; p=$ 0.049 ) decreased significantly. ${ }^{25}$ A Class II RCT $(\mathrm{N}=337 \text {, all MS types, } 15 \text { weeks })^{26}$ observed that tremor did not improve with Sativex.

Conclusions. Sativex oromucosal cannabinoid spray is probably effective for improving subjective spasticity symptoms ( 6 weeks, 1 Class ${ }^{23}$ ), pain ( 5 weeks, 1 Class $\left.\mathrm{I}^{24}\right)$, and urinary frequency (10 weeks, 1 Class $\mathrm{I}^{25}$ ).

Sativex oromucosal cannabinoid spray is probably ineffective for reducing objective spasticity measures over 6 weeks (1 Class $\mathrm{I}^{23}$ ) or bladder incontinence episodes over 10 weeks (1 Class ${ }^{25}$ ).

Sativex oromucosal spray is possibly ineffective for reducing MS-related tremor over 15 weeks $\left(1\right.$ Class $\mathrm{II}^{26}$ ).

Smoked cannabis. We reviewed 2 Class III studies. ${ }^{31,32}$

One Class III crossover study ${ }^{31}$ (37 patients, RRMS and SPMS, 2 weeks), reported spasticity reduction (modified Ashworth scale) in the cannabis group (standardized effect size 2.74, 2.2-3.14). Pain, the secondary outcome measure, also improved. After cannabis treatment, the subjects consistently showed reduced cognitive performance (Paced Auditory Serial Addition Test). ${ }^{33}$

A second Class III study ${ }^{32}(\mathrm{~N}=20$, MS type unspecified) found that both normal subjects and patients with MS fared worse on measures of posture and balance 10 minutes after smoking 1 marijuana cigarette. After Bonferroni correction, the effect was significant only for patients with MS $(p=0.018)$.

Conclusions. Data are inadequate to determine the safety or efficacy of smoked cannabis used for spasticity/pain (1 Class III ${ }^{31}$ ), balance/posture (1 Class III $^{32}$ ), and cognition (1 Class III $^{31}$ ). 
Table 2 CAM therapies with sufficient evidence to support practice recommendations in multiple sclerosis

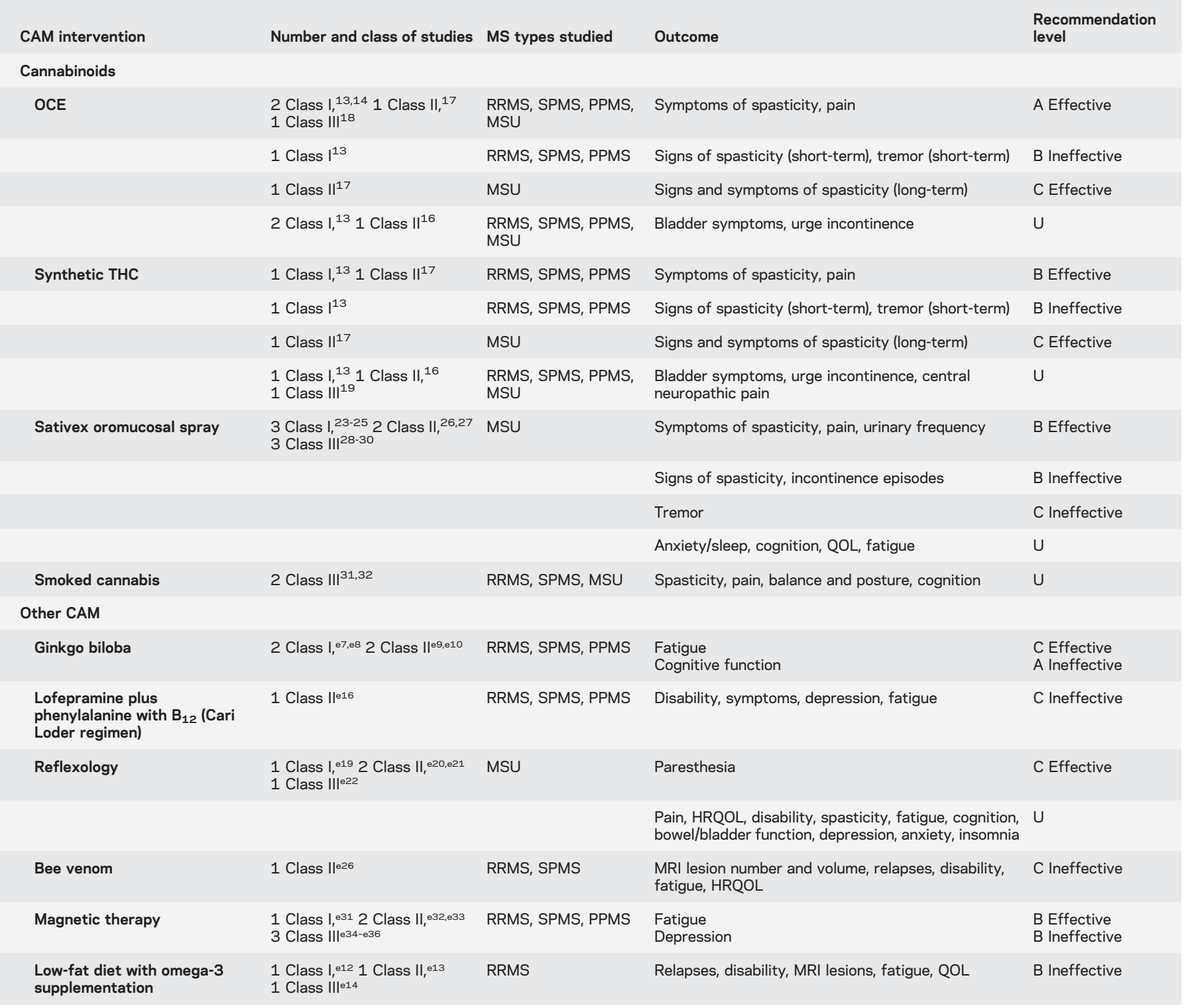

Abbreviations: $\mathrm{CAM}=$ complementary and alternative medicine; $\mathrm{HRQOL}=$ health-related QOL; MS = multiple sclerosis; MSU = MS type unspecified; OCE = oral cannabis extract; PPMS = primary progressive MS; QOL = quality of life; RRMS = relapsing-remitting MS; SPMS = secondary progressive MS; THC = tetrahydrocannabinol. $A=$ established as effective or ineffective; $B=$ probably effective or ineffective; $C=$ possibly effective or ineffective; $U=$ insufficient evidence to determine effectiveness or ineffectiveness.

Studies cited using reference list in summary guideline article (appearing in print) and e-references for print article (online data supplement).

Cannabinoid practice recommendations. Clinicians might offer OCE to patients with MS to reduce patientreported symptoms of spasticity and pain (excluding central neuropathic pain) (Level A) and might counsel patients that this symptomatic benefit is possibly maintained for 1 year (Level C), although OCE is probably ineffective for improving objective spasticity measures (short-term) or tremor (Level B).

Clinicians might offer THC to patients with MS to reduce patient-reported symptoms of spasticity and pain (excluding central neuropathic pain) (Level B). Clinicians might counsel patients that this symptomatic benefit is possibly maintained for 1 year (Level C), although
THC is probably ineffective for improving objective spasticity measures (short-term) or tremor (Level B).

Clinicians might offer Sativex oromucosal cannabinoid spray (nabiximols), where available, to reduce symptoms of spasticity, pain, or urinary frequency, although it is probably ineffective for improving objective spasticity measures or number of urinary incontinence episodes (Level B).

Clinicians might choose not to offer Sativex oromucosal cannabinoid spray to reduce MS-related tremor (Level C).

Data are inadequate to support or refute use of the following in MS (Level U): 
1. OCE/THC for bladder urge incontinence and overall symptoms

2. Synthetic THC (Marinol) for central neuropathic pain

3. Sativex oromucosal cannabinoid spray for overall bladder symptoms, anxiety symptoms/sleep problems, cognitive symptoms, quality of life (QOL), and fatigue

4. Smoked cannabis for spasticity, pain, balance/posture, and cognition

Data are inadequate to determine the abuse potential or effect on psychopathologic symptoms of Sativex cannabinoid spray (Level U).

Clinical context. The cannabinoid studies have limitations that physicians and patients must be aware of. Most studies were of short duration (6-15 weeks). Another limitation was the potential for central side effects to unmask patients to treatment assignmenta concern with regard to all masked trials involving treatments with prominent side effects. It is also important to recognize that the Ashworth scale used for objective measurement may be insensitive to spasticity changes. These factors may contribute to the discordant effects of cannabinoids on subjective and objective spasticity measures.

Adverse effects. Cannabinoids were generally well tolerated, although some SAEs were reported. Few studies reported deaths in the cannabinoid-treated groups (1 due to pneumonia, ${ }^{13} 1$ to seizure-related aspiration pneumonia, and 2 to cancer, presumed unrelated $^{16}$ ). Mild/moderate adverse effects (AEs) were common (approximately $50 \%-80 \%$ of subjects) and appeared to be equally prevalent in subjects receiving cannabinoids or placebo. No significant laboratory, hematologic, urologic, or cardiac changes, or differences in vital signs, were noted. CNS AEs (e.g., dizziness, somnolence, drowsiness, lightheadedness, memory disturbance, difficulty concentrating) were more common in subjects receiving cannabinoids vs placebo. Dizziness was most common (15\%-50\% of subjects). ${ }^{13,15,17,20,21,24-26,28,30}$ Gastrointestinal AEs, including increased appetite, nausea, vomiting, constipation, and dry/sore mouth, occurred in about $10 \%$ of subjects receiving cannabinoids ${ }^{15}$ and were more common in those receiving cannabinoids than placebo. Other less common AEs included myalgia, increased spasticity, seizures (4/137 subjects had seizures), ${ }^{23}$ lower limb weakness, hemorrhagic cystitis, dehydration, temporary psychosis (1 rated as severe), ${ }^{21}$ hallucinations, ${ }^{24}$ and oral ulceration. ${ }^{23}$

Because cannabinoids have known psychoactive properties, their potential for psychopathologic and neurocognitive AEs is a concern, especially in a patient population that may be vulnerable due to underlying disorders. Depression and predisposal to psychosis have been reported with long-term cannabis exposure. ${ }^{34-36}$ Development of marijuana addiction is controversial; however, long-term heavy marijuana use has been associated with tolerance and dependence. ${ }^{37-39}$ Evidence is also available, albeit inconsistent, for impairments in memory, concentration, and executive functions in chronic cannabis users, although it remains unclear how long these deficits persist after abstinence and whether there is permanent neurotoxicity. ${ }^{40, \mathrm{el}-\mathrm{e} 3} \mathrm{In}$ 1 study, patients with MS and prolonged use of "street" cannabis had cognitive function impairments relative to patients with MS who did not use cannabis. ${ }^{e 4}$ Patients with MS who smoked cannabis regularly had more extensive cognitive abnormalities and were more likely to meet criteria for a lifetime $D S M-I V$ psychiatric diagnosis. ${ }^{e 5}$ Although not generalizable to medical cannabis, the associations from these studies of street cannabis raise concerns. A substudy of the large Class I study reviewed here, ${ }^{13}$ available only in abstract form, reported a significant reduction in verbal learning and memory in patients with MS receiving cannabis extracts vs those receiving placebo. ${ }^{\mathrm{e} 6}$ Several of the reviewed studies assessed psychopathology and cognition as secondary outcomes without significant AEs; however, these studies were short-term and inadequately powered to exclude an effect. ${ }^{15,21,24,28}$

Clinicians should therefore counsel patients about the potential for psychopathologic/cognitive and other AEs associated with cannabinoids. Sativex oromucosal cannabinoid spray is not US Food and Drug Administration (FDA) approved and is unavailable in the United States. In the United States, caution should be exercised with regard to extrapolation of results of trials of standardized OCEs (which are unavailable commercially) to other nonstandardized, nonregulated cannabis extracts (which may be commercially available in states with medical marijuana laws).

Ginkgo biloba. We reviewed 4 studies (2 Class I, ${ }^{\mathrm{e} 7, \mathrm{e} 8} 2$ Class $\left.\mathrm{II}^{\mathrm{e} 9, \mathrm{e} 10}\right)$. A Class I RCT evaluating cognitive function ( $\mathrm{N}=39$; RRMS, SPMS, PPMS) found that subjects taking GB $120 \mathrm{mg}$ twice a day for 12 weeks had a 4.5-second greater (95\% CI -7.6-0.9, $p=$ 0.015 , nonsignificant $[p<0.008$ significant per authors] after Bonferroni correction) improvement in the Stroop Color Word test than those taking placebo. ${ }^{\text {e7 }}$ A second Class I study ( $\mathrm{N}=121$; RRMS, PPMS, SPMS, relapsing-progressive MS; 12 weeks) also found no difference in cognition measures with GB 120-mg administration twice a day compared with placebo, confirming the pilot study results. ${ }^{\text {e8 }}$

The Class II study ( $\mathrm{N}=22$, all MS types) found significantly greater fatigue reduction with GB $240 \mathrm{mg} /$ day for 4 weeks relative to placebo (Modified Fatigue Impact Scale [MFIS] ${ }^{\mathrm{e} 11}$ baseline: GB $37.8 \pm$ 14.7, placebo $39.8 \pm 15.1$; postintervention: GB 
$35.5 \pm 13.9$, placebo $42.4 \pm 15.6 ; p=0.024) .{ }^{e 9} \mathrm{~A}$ Class II follow-up analysis ${ }^{\mathrm{e} 10}$ of the data from this study did not reveal a difference between the GB and placebo groups on visual-spatial memory and attention/concentration.

GB was well tolerated in all studies. No hemorrhagic AEs were reported.

Conclusions. GB is established as ineffective for improving cognitive function in MS (12 weeks, 2 Class $\mathrm{I}^{\mathrm{e}, e 8}$ ).

GB is possibly effective over 4 weeks for reducing fatigue in MS (1 Class $\left.\mathrm{II}^{\mathrm{eq}}\right)$.

GB practice recommendations. Clinicians might counsel patients with MS that GB is established as ineffective for improving cognitive function (Level A).

Clinicians might counsel patients with MS that $\mathrm{GB}$ is possibly effective for reducing fatigue (Level C).

Clinical context. GB and other supplements are not FDA regulated. Their quality control may play a role in their effectiveness and AE risk. Moreover, interactions of supplements with other medications, especially disease-modifying therapies for MS, are a clinical concern.

Low-fat diet with omega-3 fatty acid supplementation (omega-3). We reviewed 3 studies (1 Class I, ${ }^{\mathrm{e} 2} 1$ Class $\mathrm{II},{ }^{\mathrm{e} 13}$ and 1 Class III $\left.{ }^{\mathrm{e} 14}\right)$. The Class I study (RRMS, $\mathrm{N}=92)$ of omega-3 fatty acids $(1,350 \mathrm{mg}$ eicosapentaenoic acid and $850 \mathrm{mg}$ docosahexaenoic acid daily) revealed no difference in the cumulative number of gadolinium-enhancing MRI lesions at 6 months, relapse rates at 6 and 24 months, disability progression, fatigue, or QOL. ${ }^{\mathrm{e} 12}$

The Class II study (1-year underpowered RCT, $\mathrm{N}=27, \mathrm{RRMS})^{\mathrm{e} 13}$ evaluated a low-fat diet supplemented with either omega-3 fatty acid (fish oil) or olive oil. There was no significant difference in healthrelated QOL (HRQOL), relapse rates, or disability. ${ }^{\mathrm{e} 13}$

Conclusion. A low-fat diet with fish oil supplementation is probably ineffective for reducing MS-related relapse, disability, or MRI lesions, or for improving fatigue or QOL (RRMS, 1 Class I). ${ }^{\text {e12 }}$

Omega-3 practice recommendation. Clinicians might counsel patients that a low-fat diet with fish oil supplementation is probably ineffective for reducing relapses, disability, or MRI lesions, or for improving fatigue or QOL in MS (Level B).

Lofepramine. Lofepramine (a tricyclic antidepressant structurally related to imipramine and desipramine) combined with L-phenylalanine and IM vitamin $\mathrm{B}_{12}$ is known as the Cari Loder regimen. ${ }^{\text {e15 }}$ One 24-week Class II RCT ( $\mathrm{N}=138$, all MS subtypes) compared the Cari Loder regimen with placebo pills and IM vitamin $\mathrm{B}_{12}$ (1 mg weekly). ${ }^{\mathrm{e} 16}$ The primary outcome measures of disability did not change significantly (Guy's
Neurological Disability Scale [GNDS] $]^{\mathrm{e} 17}-1.16[95 \%$ CI -2.75 to 0.43 ], Expanded Disability Status Scale [EDSS] $^{\mathrm{e} 18}-0.17$ [95\% CI -0.39 to 0.05$\left.]\right)$. There was a small improvement in fatigue and symptoms, nonsignificant with Bonferroni correction. Depression did not improve.

Conclusion. The Cari Loder regimen is possibly ineffective for reducing MS-related disability, symptoms, depression, or fatigue (all MS subtypes, 1 Class $\mathrm{II}^{\mathrm{e} 16}$ ).

Lofepramine practice recommendation. Clinicians might counsel patients with MS that lofepramine plus L-phenylalanine with vitamin $B_{12}$ (Cari Loder regimen) is possibly ineffective for treating disability, symptoms, depression, or fatigue (Level C).

Reflexology. Reflexology involves applying manual pressure to points on the feet. We evaluated 4 studies (1 Class I, ${ }^{\mathrm{e} 19} 2$ Class II, ${ }^{\mathrm{e} 20, \mathrm{e} 21}$ and 1 Class III ${ }^{\mathrm{e} 22}$ ).

The Class I study (underpowered RCT; $\mathrm{N}=$ 71; RRMS, SPMS, PPMS) compared 10 weekly 45-minute sessions of sham reflexology (foot massages) with precision reflexology. ${ }^{\mathrm{e} 19}$ Both groups showed reductions in pain (VAS), disability (Roland Morris Disability Questionnaire ${ }^{\mathrm{e} 3}$ ), spasticity (VAS), fatigue (Multiple Sclerosis Impact Scale [MSIS], ${ }^{\text {e2 }}$ Fatigue Severity Scale [FSS], MFIS), and depression (Beck Depression Inventory $\left.{ }^{\mathrm{e} 25}\right)$. Differences between groups were nonsignificant. ${ }^{\text {e19 }}$

One Class II RCT (MS type unspecified, $\mathrm{N}=71$ ) found significantly greater reductions in paresthesia, urinary symptoms, and spasticity (Ashworth Scale) with 11 weekly reflexology treatments plus calf massage relative to calf massage alone. ${ }^{\text {20 }}$ After Bonferroni correction, only the difference in paresthesia reduction remained significant (mean \pm SD difference pre-/posttreatment in treated group $-1.49 \pm 2.1$, controls $0.16 \pm 2.1 ; p=0.04$ ).

Another Class II RCT (underpowered; SPMS, PPMS; $\mathrm{N}=20 ; 16$ weeks) of reflexology compared with sham treatments did not reveal improvement in the primary outcome of HRQOL (change in MSIS: 17; $95 \% \mathrm{CI}-4.121$ to $40.21, p=0.112$ ). Secondary outcomes of pain, spasticity, sleep, mood, and bowel/ bladder function also did not change. ${ }^{\text {e21 }}$

Conclusions. Reflexology is possibly effective for reducing MS-associated paresthesia over 11 weeks (MS type unspecified, 1 Class $\mathrm{II}^{\mathrm{e} 20}$ ).

Data are inadequate to support or refute the use of reflexology for pain, HRQOL, disability, spasticity, fatigue, cognition, bowel/bladder function, depression, anxiety, or insomnia in MS.

Reflexology practice recommendation. Clinicians might counsel patients with MS that reflexology is possibly effective for reducing paresthesia (Level C).

Bee venom. One Class II crossover study ${ }^{\mathrm{e} 26}$ of bee venom (20 stings from live bees 3 times weekly for 24 weeks $)(\mathrm{N}=26$; RRMS, SPMS $)$ found no 
significant effect on the number of new gadoliniumenhancing lesions on MRI, volume of enhancing lesions, total lesion volume, relapses, disability (EDSS, Multiple Sclerosis Functional Composite, ${ }^{\text {e27 }}$ GNDS), fatigue (Shortened Fatigue Questionnaire, ${ }^{\text {e28 }}$ Fatigue Impact Scale ${ }^{\mathrm{e} 29}$ ), or HRQOL (Short Form-36 ${ }^{\mathrm{e} 30}$ ). AEs included tenderness, swelling, and redness at the sting sites; itching (4 subjects); and flu-like symptoms (5 subjects). ${ }^{\text {e26 }}$

Conclusion. Bee sting therapy is possibly ineffective for reducing MS-related relapses, disability, fatigue, total MRI lesion burden, new gadolinium-enhancing lesion volume, or HRQOL (RRMS, SPMS; 1 Class II). ${ }^{\text {e26 }}$

Bee venom practice recommendation. Clinicians might counsel patients with MS that bee sting therapy is possibly ineffective for reducing relapses, disability, fatigue, total MRI lesion burden, new gadoliniumenhancing lesion volume, or HRQOL (Level C).

Clinical context. Bee stings can be associated with anaphylactic reaction and possible death.

Magnetic therapy. The search identified 6 studies (1 Class $\mathrm{I}^{\mathrm{e}}{ }^{31} 2$ Class II, ${ }^{\mathrm{e} 32, \mathrm{e} 33}$ and 3 Class III $\left.{ }^{\mathrm{e} 34-\mathrm{e} 36}\right)$.

The Class I 12-week RCT ( $\mathrm{N}=41$, RRMS) reported significantly less fatigue (MFIS) with lowfrequency pulsed electromagnetic field therapy (bioelectromagnetic-energy-regulation device, in the form of a metal mat upon which subjects lay for 8 minutes twice a day) (active 26.84 \pm SE 12.061, placebo $36.67 \pm 13.253 ; p=0.024)$. Fatigue, measured by FSS, a secondary outcome measure, also decreased in the treated group (FSS mean [SD]: placebo 4.7 [1.6], treatment 3.5 [1.3], $t=-2.53 ; p=0.016)$. There was no change in depression or disability (EDSS). ${ }^{\text {e31 }}$ However, an EDSS change may not have been detected because of the study's short duration (EDSS may be insensitive to change in short-term disability).

A Class II underpowered RCT ${ }^{\mathrm{e} 32}(\mathrm{~N}=30, \mathrm{RRMS} /$ progressive MS) found no significant change after Bonferroni correction in disability (EDSS) or patientreported performance scale related to bladder control, cognition, fatigue, mobility, sensation, spasticity, vision, total performance, or hand function between subjects wearing wristwatch-size magnetic pulsing devices (Enermed device) (10-24 hours/day for 2 months) or inactive devices.

Another Class II underpowered RCT ( $\mathrm{N}=50$; RRMS, SPMS, PPMS) found no significant difference in fatigue (MFIS, FSS) with low-frequency magnetic stimulation 3 sessions per week for 8 weeks (intensity $37.5 \mathrm{mT}$ and a sequence of pulses at 4-7 Hz). ${ }^{\text {33 }} \mathrm{Mag}$ netic therapy was generally well tolerated; most studies reported no AEs. ${ }^{\text {e34,e36 }}$ One study reported headache, spasms, and burning sensation. e32 $^{2}$

Conclusions. Magnetic therapy is probably effective for reducing fatigue in RRMS (1 Class I, ${ }^{\mathrm{e} 31} 1$ Class
III $\left.^{\mathrm{e34}}\right)$ and probably ineffective for reducing depression in RRMS over 15 weeks (1 Class $\left.I^{\mathrm{e} 31}\right)$.

Data are inadequate to support or refute the effect of magnetic therapy on reducing MS-related disability (1 Class $\mathrm{I}^{\mathrm{e} 31}$ with insensitive outcome measure; 1 underpowered Class $\mathrm{II}^{\mathrm{e} 32}$ ), bladder control problems, or spasticity, or on improving cognition, mobility, sensation, or vision ( 1 underpowered Class II, ${ }^{\mathrm{e} 2} 3$ underpowered/inconsistent Class III ${ }^{\text {34-e36) }}$.

Magnetic therapy practice recommendation. Clinicians might counsel patients with MS that magnetic therapy is probably effective for reducing fatigue (Level B) and probably ineffective for reducing depression (Level B).

Other CAM therapies practice recommendation. Clinicians should counsel patients with MS that the safety and efficacy of other reviewed CAM, or the interaction of CAM with disease-modifying therapies for MS, are unknown Level U).

LIMITATIONS This review has several limitations. Because the search strategy is limited only to MS, some potentially important AEs (e.g., bleeding risk with GB) ${ }^{\text {e37 }}$ of the reviewed therapies noted when they were evaluated in other diseases were not apparent in the MS population. Therapies that have received much press attention (e.g., dental amalgam removal, transdermal histamine) have little evidence to support recommendations.

\section{AUTHOR CONTRIBUTIONS}

Vijayshree Yadav: study concept and design, acquisition of data, analysis or interpretation of data, drafting/revising the manuscript, critical revision of the manuscript for important intellectual content, study supervision. Christopher Bever, Jr.: study concept and design, acquisition of the data, analysis and interpretation of the data, review of the manuscript for important intellectual content. James Bowen: study concept and design, analysis or interpretation of data, critical revision of the manuscript for important intellectual content. Allen Bowling: study concept and design, analysis or interpretation of data, critical revision of the manuscript for important intellectual content. Bianca Weinstock-Guttman: study concept and design, analysis or interpretation of data, critical revision of the manuscript for important intellectual content. Michelle Cameron: analysis or interpretation of data, critical revision of the manuscript for important intellectual content. Dennis Bourdette: study concept and design, acquisition of data, analysis or interpretation of data, critical revision of the manuscript for important intellectual content, study supervision. Gary Gronseth: study concept and design, acquisition of data, analysis or interpretation of data, drafting/revising the manuscript, critical revision of the manuscript for important intellectual content, study supervision. Pushpa Narayanaswami: study concept and design, acquisition of data, analysis or interpretation of data, drafting/revising the manuscript, critical revision of the manuscript for important intellectual content, study supervision.

\section{STUDY FUNDING}

This guideline was developed with financial support from the American Academy of Neurology. None of the authors received reimbursement, honoraria, or stipends for their participation in development of this guideline.

\section{DISCLOSURE}

V. Yadav serves as a section editor for Current Neurology and Neuroscience Reports, served as consultant for Bayer Healthcare Pharmaceutical and Biogen Idec, is on the speakers' bureau of Novartis, and receives research support from the McDougall Foundation, National Multiple Sclerosis 
Society (NMSS) Foundation, Nancy Davis Center Without Walls Foundation, and Biogen Idec. C. Bever received travel funding from the American Academy of Neurology (unrelated to this guideline), the University of Maryland School of Medicine, and the Department of Veterans Affairs; has a patent held or pending for use of hematogenous stem cells in neuronal replacement therapy and gene delivery; has received funding for merit grants from the US Department of Veterans Affairs and a pilot grant from the NMSS; and has received license fee payments and royalty payments (or has contractual rights for receipt of future royalty payments) related to the patent disclosed above. Dr. Bever's spouse has received publishing royalties from Ambulatory Medicine, Barker et al. J. Bowen reports no relevant disclosures. A. Bowling has received funding for travel and honoraria from the Consortium of Multiple Sclerosis Centers, the NMSS, the Multiple Sclerosis Foundation, ProCE, the Center for Disability Services, and the Mandell Center for MS; has received research support from Biogen Idec and Novartis; has consulted for Questcor; and serves on the speakers' bureaus of Acorda, Bayer, Biogen Idec, EMD Serono, Genzyme, Novartis, Pfizer, and Teva Neurosciences. B. Weinstock-Guttman has served on speakers' bureaus and as a consultant for Biogen Idec, Teva Neurosciences, EMD Serono, Pfizer, Novartis, Genzyme, Sanofi, Mylan, and Acorda; and has received grant/research support from the agencies listed above as well as from Questcor and Shire. M. Cameron has received research support from the US Department of Veterans Affairs, the NMSS, the Collins Foundation, Acorda Therapeutics, and the Multiple Sclerosis International Federation and funding for travel and honoraria from the Consortium of Multiple Sclerosis Centers. D. Bourdette has received speaker honoraria and consulting fees from Biogen Idec and Teva Neurosciences, consulting fees from Elan Pharmaceuticals, speaker honoraria from Genzyme, and research grants from the US Department of Veterans Affairs, National Institutes of Health, and NMSS. G. Gronseth and P. Narayanaswami report no relevant disclosures. Go to Neurology.org for full disclosures.

\section{DISCLAIMER}

This statement is provided as an educational service of the American Academy of Neurology. It is based on an assessment of current scientific and clinical information. It is not intended to include all possible proper methods of care for a particular neurologic problem or all legitimate criteria for choosing to use a specific procedure. Neither is it intended to exclude any reasonable alternative methodologies. The AAN recognizes that specific patient care decisions are the prerogative of the patient and the physician caring for the patient, based on all of the circumstances involved. The clinical context section is made available in order to place the evidence-based guideline(s) into perspective with current practice habits and challenges. Formal practice recommendations are not intended to replace clinical judgment.

\section{CONFLICT OF INTEREST}

The American Academy of Neurology is committed to producing independent, critical and truthful clinical practice guidelines (CPGs). Significant efforts are made to minimize the potential for conflicts of interest to influence the recommendations of this CPG. To the extent possible, the AAN keeps separate those who have a financial stake in the success or failure of the products appraised in the CPGs and the developers of the guidelines. Conflict of interest forms were obtained from all authors and reviewed by an oversight committee prior to project initiation. AAN limits the participation of authors with substantial conflicts of interest. The AAN forbids commercial participation in, or funding of, guideline projects. Drafts of the guideline have been reviewed by at least 3 AAN committees, a network of neurologists, Neurology peer reviewers and representatives from related fields. The AAN Guideline Author Conflict of Interest Policy can be viewed at www.aan.com. For complete information on this process, access the 2004 AAN process manual. ${ }^{12}$

Received August 21, 2013. Accepted in final form December 4, 2013.

\section{REFERENCES}

1. Berkman CS, Pignotti MG, Pamela FC. Use of alternative treatments by people with multiple sclerosis. Neurorehab Neural Re 1999;13:243-254.
2. Schwartz CE, Laitin E, Brotman S, LaRocca N. Utilization of unconventional treatments by persons with MS: is it alternative or complementary? Neurology 1999;52:626-629.

3. Marrie RA, Hadjmichael O, Vollmer T. Predictors of alternative medicine use by multiple sclerosis patients. Mult Scler 2003;9:461-466.

4. Nayak S, Matheis RJ, Schoenberger NE, Shiflett SC. Use of unconventional therapies by individuals with multiple sclerosis. Clin Rehab 2003;17:181-191.

5. Stuifbergen AK, Harrison TC. Complementary and alternative therapy use in persons with multiple sclerosis. Rehab Nurs 2003;28:141-147.

6. Apel A, Greim B, Zettl UK. How frequently do patients with multiple sclerosis use complementary and alternative medicine? Complement Therapies Med 2005;13: 258-263.

7. Apel A, Greim B, Konig N, Zettl UK. Frequency of current utilisation of complementary and alternative medicine by patients with multiple sclerosis. J Neurol 2005;253:1331-1336.

8. Yadav V, Shinto L, Morris C. Use and self reported benefit of complementary and alternative (CAM) therapies among multiple sclerosis patients. Int J MS Care 2006;8:5-10.

9. Schwarz S, Knorr C, Geiger H. Complementary and alternative medicine for multiple sclerosis. Mult Scler 2008;14:1113-1119.

10. Leong EM, Semple SJ, Angley M, Siebert W, Petkov J, McKinnon RA. Complementary and alternative medicines and dietary interventions in multiple sclerosis: what is being used in South Australia and why? Complement Ther Med 2009;17:216-223.

11. Shinto L, Yadav V, Morris C. Demographic and healthrelated factors associated with complementary and alternative medicine (CAM) use in multiple sclerosis. Mult Scler 2006;12:94-100.

12. AAN (American Academy of Neurology). Clinical Practice Guideline Process Manual, St Paul, MN: The American Academy of Neurology; 2004.

13. Zajicek J, Fox P, Sanders H, et al. Cannabinoids for treatment of spasticity and other symptoms related to multiple sclerosis (CAMS study): multicentre randomised placebocontrolled trial. Lancet 2003;362:1517-1526.

14. Zajicek JP, Hobart JC, Slade A, Barnes D, Mattison PG; for MUSEC Research Group. Multiple Sclerosis and Extract of Cannabis: results of the MUSEC trial. J Neurol Neurosurg Psychiatry 2012;83:1125-1132.

15. Vaney C, Heinzel-Gutenbrenner M, Jobin P, et al. Efficacy, safety and tolerability of an orally administered cannabis extract in the treatment of spasticity in patients with multiple sclerosis: a randomized, double-blind, placebocontrolled, crossover study. Mult Scler 2004;10:417-424.

16. Freeman RM, Adekanmi O, Waterfield MR, et al. The effect of cannabis on urge incontinence in patients with multiple sclerosis: a multicentre, randomised placebo-controlled trial (CAMS-LUTS). Int Urogynecol J Pelvic Floor Dysfunct 2006;17:636-641.

17. Zajicek JP, Sanders HP, Wright DE, et al. Cannabinoids in multiple sclerosis (CAMS) study: safety and efficacy data for 12 months follow up. J Neurol Neurosurg Psychiatry 2005;76:1664-1669.

18. Ungerleider JT, Andrysiak T, Fairbanks L, Ellison GW, Myers LW. Delta-9-THC in the treatment of spasticity associated with multiple sclerosis. Adv Alcohol Substance Abuse 1987;7:39-50.

19. Svendsen KB, Jensen TS, Bach FW. Does the cannabinoid dronabinol reduce central pain in multiple sclerosis? 
Randomised double blind placebo controlled crossover trial. BMJ 2004;329:253.

20. Fox P, Bain PG, Glickman S, Carroll C, Zajicek J. The effect of cannabis on tremor in patients with multiple sclerosis. Neurology 2004;62:1105-1109.

21. Killestein J, Hoogervorst ELJ, Reif M, et al. Safety, tolerability, and efficacy of orally administered cannabinoids in MS. Neurology 2002;58:1404-1407.

22. Bohannon R, Smith M. Interrater reliability of a modified Ashworth scale of muscle spasticity. Phys Ther 1987;67:206.

23. Wade DT, Makela P, Robson P, House H, Bateman C. Do cannabis-based medicinal extracts have general or specific effects on symptoms in multiple sclerosis? A doubleblind, randomized, placebo-controlled study on 160 patients. Mult Scler 2004;10:434-441.

24. Rog DJ, Nurmikko TJ, Friede T, Young CA. Randomized, controlled trial of cannabis-based medicine in central pain in multiple sclerosis. Neurology 2005;65:812-819.

25. Kavia RB, De Ridder D, Constantinescu CS, Stott CG, Fowler CJ. Randomized controlled trial of Sativex to treat detrusor overactivity in multiple sclerosis. Mult Scler 2010;11:1349-1359.

26. Collin C, Davies P, Mutiboko IK, Ratcliffe S; Sativex Spasticity in MS Study Group. Randomized controlled trial of cannabis-based medicine in spasticity caused by multiple sclerosis. Eur J Neurol 2007;14:290-296.

27. Collin C, Ehler E, Waberzinek G, et al. A double-blind, randomized, placebo-controlled, parallel-group study of Sativex, in subjects with symptoms of spasticity due to multiple sclerosis. Neurol Res 2010;32:451-459.

28. Wade DT, Makela PM, House H, Bateman C, Robson P. Long-term use of a cannabis-based medicine in the treatment of spasticity and other symptoms in multiple sclerosis. Mult Scler 2006;12:639-645.
29. Aragona M, Onesti E, Tomassini V, et al. Psychopathological and cognitive effects of therapeutic cannabinoids in multiple sclerosis: a double-blind, placebo controlled, crossover study. Clin Neuropharmacol 2009;32:41-47.

30. Centonze D, Mori F, Koch G, et al. Lack of effect of cannabis-based treatment on clinical and laboratory measures in multiple sclerosis. Neurol Sci 2009;30:531-534.

31. Corey-Bloom J, Wolfson T, Gamst A, et al. Smoked cannabis for spasticity in multiple sclerosis: a randomized, placebo-controlled trial. CMAJ 2012;184:1143-1150.

32. Greenberg HS, Werness SA, Pugh JE, Andrus RO, Anderson DJ, Domino EF. Short-term effects of smoking marijuana on balance in patients with multiple sclerosis and normal volunteers. Clin Pharmacol Ther 1994;55:324-328.

33. Gronwall DM. Paced auditory serial-addition task a measure of recovery from concussion. Percept Mot Skills 1977;44: 367-373.

34. Bovasso GB. Cannabis abuse as a risk factor for depressive symptoms. Am J Psychiatry 2001;158:2033-2037.

35. Johns A. Psychiatric effects of cannabis. Br J Psychiatry 2001;178:116-122.

36. Nunez LA, Gurpegui M. Cannabis-induced psychosis: a cross-sectional comparison with acute schizophrenia. Acta Psychiatry Scand 2002;10:173-178.

37. Iversen L. Cannabis and the brain. Brain 2003;126: 1252-1270.

38. Budney AJ, Hughes JR, Moore BA, et al. Review of the validity and significance of cannabis withdrawal syndrome. Am J Psychiatry 2004;161:1967-1977.

39. Budney AJ, Hughes JR. The cannabis withdrawal syndrome. Curr Opin Psychiatry 2006;19:233-238.

40. Pope HG Jr, Gruber AJ, Hudson JI, et al. Neuropsychological performance in long-term cannabis users. Arch Gen Psychiatry 2001;58:909-915. 


\section{Neurology}

\section{Summary of evidence-based guideline: Complementary and alternative medicine in multiple sclerosis: Report of the Guideline Development Subcommittee of the American Academy of Neurology}

Vijayshree Yadav, Christopher Bever, Jr, James Bowen, et al.

Neurology 2014;82;1083-1092

DOI 10.1212/WNL.0000000000000250

\section{This information is current as of March 24, 2014}

\section{Updated Information \& Services}

Supplementary Material

\section{References}

Citations

Subspecialty Collections

Permissions \& Licensing

Reprints including high resolution figures, can be found at: http://www.neurology.org/content/82/12/1083.full.html

Supplementary material can be found at: http://www.neurology.org/content/suppl/2014/03/22/82.12.1083.DC1 http://www.neurology.org/content/suppl/2014/03/22/82.12.1083.DC2

This article cites 39 articles, 11 of which you can access for free at: http://www.neurology.org/content/82/12/1083.full.html\#\#ref-list-1

This article has been cited by 2 HighWire-hosted articles: http://www.neurology.org/content/82/12/1083.full.html\#\#otherarticles

This article, along with others on similar topics, appears in the following collection(s):

Multiple sclerosis

http://www.neurology.org//cgi/collection/multiple_sclerosis

Information about reproducing this article in parts (figures,tables) or in its entirety can be found online at:

http://www.neurology.org/misc/about.xhtml\#permissions

Information about ordering reprints can be found online:

http://www.neurology.org/misc/addir.xhtml\#reprintsus

Neurology ${ }^{\circledR}$ is the official journal of the American Academy of Neurology. Published continuously since 1951, it is now a weekly with 48 issues per year. Copyright () 2014 American Academy of Neurology. All rights reserved. Print ISSN: 0028-3878. Online ISSN: 1526-632X.

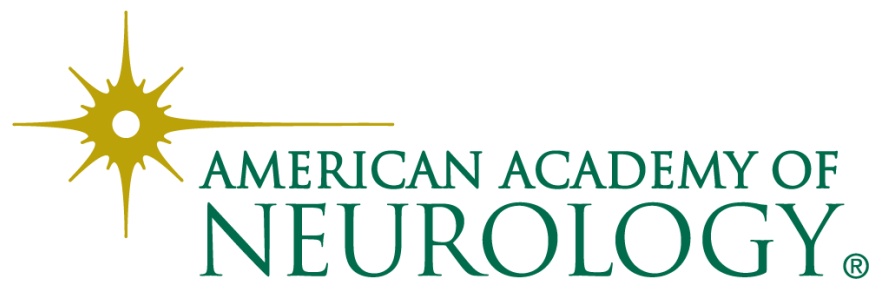

